\title{
Antioxidant activity of Ricinus Communis
}

\author{
Faheem Ahmed $^{1 *}$ and Moshin Iqbal ${ }^{2}$ \\ ${ }^{1}$ Biocell Lab, Department of Biochemistry, University of Agriculture, Pakistan \\ ${ }^{2}$ Industrial Biotechnology Lab, Department of Biochemistry, University of Agriculture, Pakistan
}

Submission: February 13, 2018; Published: March 01, 2018

"Corresponding author: Faheem Ahmed and Mohsin Iqbal, Department of Biochemistry, University of Agriculture, Faisalabad, Pakistan, Tel: 03136763676; Email: mohsiniqbal5050@gmail.com

\begin{abstract}
Medicinal plants are very important in whole world. Ricinus communis is traditionally used as antidiabetic, anti-inflammatory, antiasthmatic, anticancer and antimicrobial. Potentials of roots of Ricinus communis has been undertaken in present work by determining its antioxidant activity. For determining activity seven extracts were prepared like methanol, ethanol, aqueous, $n$-butanol, $n$-hexane, chloroform and ethyl acetate. Seven extracts were prepared from roots of Ricinus communis. For determining total phenolic contents (TPC) and Total flavonoid content (TFC) FolinCiocalteu reagent and Aluminum Chloride colorimetric methods were used. The DPPH (2, 2 Diphenyl 1 picryl hydrazyl) radical scavenging potential activity was also assessed. Standard methods were used for assessment of the antioxidant activity. ANOVA was performed to analyze the data. The ethyl acetate and chloroform gave maximum (41\%) DPPH activity. The other extracts also gave good DPPH activity but it was less than ethyl acetate and chloroform. In the TPC test aqueous, $n$-butanol and ethyl acetate extracts showed activity of $131 \mathrm{mg} / \mathrm{mL}, 127 \mathrm{mg} / \mathrm{mL}$ and $117 \mathrm{mg} / \mathrm{mL}$ respectively. Other extracts gave less activity than these and control gave $155 \mathrm{mg} / \mathrm{mL}$. In TFC activity control gave $38 \mu \mathrm{g} / \mathrm{mL}$. The methanol and aqueous showed $32 \mu \mathrm{g} / \mathrm{mL}$ each. Remaining extracts gave less activity than these. Ricinus communis is considered as a good medicinal plant.
\end{abstract}

Keywords: Ricinus communis; Extracts; Antioxidant; Phenolic compounds; Flavonoids

Abbreviations: TPC: Total Phenolic Content; TFC: Total Flavonoid Content; DPPH: 2,2 Diphenyl 1 Picryl Hydrazyl; DMSO: Dimethyl Sulfoxide; LDL: Low Density Lipoproteins; DNA: Deoxy Ribonucleic Acid; $\mathrm{H}_{2} \mathrm{O}_{2}$ : Hydrogen Per Oxide

\section{Aims and Background}

Ricinus communis is a castor plant belongs to spurge family. Its roots, leaves and seed extracts are famous for their medicinal properties. Its cultivation was stopped in the past due to some diseases caused by ricin obtained from $R$. communis. Its cultivation was again started few decades ago because of its high pharmaceutical and agricultural qualities. It shows different activities. It is plant of African origin. There are few areas like temperate regions, subtropical and tropical regions where Ricinus communis could be cultivated in bulk. The Leaves of Ricinus communis are green, purple or reddish-green, palmately lobed, broad, having 6-12 lobes, with $25-55 \mathrm{~cm}$ diameters. It is almost orbicular in shape, margin serrate, having lobes which are oblong linear, acuminate or acute, having lengthy from 2.5$7.5 \mathrm{~cm}$ in width $4-20 \mathrm{~cm}$, cylindrical or slightly flattened towards distal and palmately attached to blade, petiole $10-20 \mathrm{~cm}$ long, solid when young, alternate, becomes hollow on maturity smooth, palmately-divided and $25-55 \mathrm{~cm}$ in width. They have lobes which are toothed and oblong [1].

In 18th century the investigation on the properties, characteristics, sources and use of antioxidant compounds especially flavonoids, vitamins, synthetic chemicals, micronutrients and phenolic compounds was started. It has given us the way to rampant use of antioxidant compounds for the purpose of obtaining and preserving the proper human health. There are many food supplements and nutraceuticals which contain natural or synthetic antioxidant compounds. There are some problems about using antioxidants because many beliefs of people from ancient times. They consider them dangerous. But in many countries, they are in use from ancient times against many diseases. The common methods for checking in vitro antioxidant capacity and nonenzymatic biochemical present in specific phenolic substances and nonphenolic substances to check the activity of antioxidants present in herbs [2].

There are many good effects shown by antioxidant compounds on vascular system which are analyzed both in vitro and in vivo against atherosclerosis. Antioxidants are good if they are used for short time span but if they are used as long term in human then their effect is controversial and it can be dangerous. The vitamin $\mathrm{C}$ and vitamin $\mathrm{E}$ have combined effect against carotid atherosclerosis. They are analyzed for three years and their treatment proves to be effective treatment. The antioxidants have good effect against low density lipoproteins (LDL) because they oxidize them. The endothelial flow has been investigated during this study. The antioxidant study of heart 
was done at Cambridge. The antioxidants are also studied for end stage renal diseases, cholesterol lowering atherosclerosis and cardiovascular diseases. The antioxidants are proved as quite effective against cardiovascular diseases. These antioxidants are good and effective but they are not recommended for longer period of time. The multiple antioxidants normally work in very effective manner. It has seen that the vitamin $\mathrm{E}$ alone has no effect on cardiovascular diseases. The dosage of antioxidants should be normal.

The high dosage of vitamin E can cause death. It does not increase huge risk of mortality but its high dosage can cause death of patient. The atherosclerosis can be due to the stress caused by oxidants and antioxidants show good results against them. Proper dosage and medication of antioxidants is required against them. Sometimes a single antioxidant is not enough then multiple antioxidants are required there. The atherogenic is a condition in which lipids are stored in arteries. The antioxidants are also proved as anti-atherogenic because of their effective work against atherosclerosis. They have the ability to inhibit the atherosclerosis. The vitamin $\mathrm{C}$ and vitamin $\mathrm{E}$ have combined effect against the oxidation and they inhibit the oxidation of DNA by $\mathrm{H}_{2} \mathrm{O}_{2}$ in the lymphocytes of human. They enhance the endogenous plasma and tissue antioxidant defense system. They have the ability to restore endothelium dependent vasoactive. In the diabetic patients, dysfunction endothelial can be improved by antioxidants like coenzyme Q10 which has ability to carry electron in electron transport chain reaction a type of oxidative phosphorylation normally occurs in mitochondria. Selenium can be helpful in lower oxidative stress in the heart. By the coenzyme $\mathrm{Q}(\mathrm{CoQ})$ supplementation the blood pressure can be lowered and long term glycemic condition can be controlled. The antioxidant vitamin $\mathrm{E}$ has the ability to reduce the glucose level in plasma and resistance against insulin.

Vitamin C and vitamin E are quite effective against the hypertension in the hypertensive patients. Many antioxidants are present in nature but which antioxidant is effective for biochemical effects in metabolism is still not known. But lots of work explored many things about the usage of antioxidants. There are few antioxidant combinations which are specifically used for the treatment of glucose, lipid homeostasis and blood pressure. They are also good for vascular elasticity improvement. The change in humoral factors like renin, aldosterone and homocysteine are still matter of uncertainty. The dosage for these also given but no result is still there. There is no change in the levels of catecholamine in urine during the treatment. Pathophysiologic mechanism is plasma dependent. These antioxidants are dependent upon plasma concentration for their proper working like aldosterone, renin and endothelin.

The mechanism for antioxidant action on the vascular system is still very uncertain. The plasma level effect dependency by antioxidants is great work in this investigation. The effects of antioxidants for vascular action are not measured. There are patients with multiple cardiac diseases are studied in this investigation. The selenium, vitamin C, coenzyme Q10 and vitamin $\mathrm{E}$ is very useful in metabolizing the lipid and glucose. These are also useful for the patients of hypertension and diseases of arteries which have different risk factors. Antioxidant treatment is studied and its impact on human population is investigated [3]. In my work, I used potential of roots of Ricinus communis to check antioxidant activity by preparation of seven extracts of methanol, ethanol, aqueous, n-butanol, n-hexane, chloroform and ethyl acetate.

\section{Experimental}

\section{Total Phenolic Contents (TPC)}

The concentration of phenolic in the Ricinus communis extracts was determined with Folin-Ciocalteu reagent [4]. The Folin-Ciocalteau reagent is formed from a mixture of phosphotungstic acid and phosphomolybdic acid which after oxidation of the phenols, is reduced to a mixture of blue oxides of tungsten and molybdenum. The blue coloration produced has a maximum absorption in the region of $750 \mathrm{~nm}$, and is proportional to the total quantity of phenolic compounds originally present. The concentrations of phenolics in the Ricinus communis extracts were found with Folin-Ciocalteu reagent [5]. $0.5 \mathrm{~mL}$ of each sample was dissolved in $1.0 \mathrm{~mL}$ DMSO (dimethyl sulfoxide). $1.0 \mathrm{~mL}$ of $10 \%$ dilution of Folin- Ciocalteu reagent and after 3 minutes, $3 \mathrm{~mL}$ of $\mathrm{Na} 2 \mathrm{CO} 3(1 \% \mathrm{w} / \mathrm{v})$ were added and the resulting mixture was boiled for 20 minutes. Then cool and placed $200 \mu \mathrm{L}$ sample in ELISA plate and absorbance of all samples was measured at $750 \mathrm{~nm}$ using ELISA reader. The results were expressed in terms of gallic acid equivalent (mg gallic acid/g of dry mass), which is a common reference compound.

\section{Total Flavonoid Contents (TFC)}

Aluminium chloride colorimetric technique was used for flavonoids estimation [6]. The basic principle of Aluminium chloride colorimetric method is that Aluminium chloride forms acid stable complexes with the C-4 keto group and either the C-3 or C-5 hydroxyl group of flavones and flavonols. In addition, it also forms acid labile complexes with the ortho-dihydroxyl groups in the A- or B-ring of flavonoids. Aluminium chloride colorimetric technique was used for flavonoids estimation [7]. $50 \mu \mathrm{L}$ of each test sample $+1.25 \mathrm{~mL}$ distilled water $+150 \mu \mathrm{L}$ $\mathrm{NaNO}_{2}$ were added in test tubes and kept at room temperature for 10 minutes. After 10 mints added $300 \mu \mathrm{L} \mathrm{AlCl}_{3}$ after 5 mins, $1 \mathrm{~mL} \mathrm{NaOH}$ was added and incubated at room temperature for 20 mints. After incubation absorbance was read at about $510 \mathrm{~nm}$ by ELISA reader. Three readings for each sample were taken and results were averaged.

\section{DPPH Radical Scavenging Assay}

The DPPH assay was carried out as described by Queiroz et al. [8]. The antioxidant activity of extracts was assessed by measuring their scavenging abilities to 2, 2-diphenyl l-picrylhydrazyl stable radical. The principle of DPPH method is based on the reduction of DPPH in the presence of a hydrogen donating antioxidant. 
Extracts reduce the colour of DPPH due to the power of hydrogen donating ability. DPPH is one of the compounds that possess a proton free radical with a characteristic absorption, which decreases significantly on exposure to proton radical scavengers. The DPPH assay was carried out as described by Souri et al. [9]. The antioxidant activites of extracts were assessed by measuring their scavenging abilities to 2, 2-diphenyl l- picrylhydrazyl stable radical. In Eppendorf $1 \mu \mathrm{L}$ sample $+1 \mathrm{~mL}$ DPPH solution (by dissolving $0.001 \mathrm{mg}$ DPPH in $12 \mathrm{~mL}$ methanol) added and for blank added $1 \mathrm{~mL}$ DPPH solution only was then covered by aluminum foil for $30 \mathrm{~min}$. After $30 \mathrm{~min}$, the absorbance was read against a blank at $517 \mathrm{~nm}$. The assay was carried out in triplicate. $\%$ radical scavenging concentration was calculated by using the following formula:

Radical Scavenging $\left(\mathrm{IC}_{50} \%\right)=100 \times(\mathrm{A}$ blank $-\mathrm{A}$ sample $/ \mathrm{A}$ blank $)$

A blank = Absorbance of control

A sample $=$ Absorbance of test samples

IC50 value is the concentration of sample, required to scavenge $50 \%$ of DPPH free radicals. The assay was carried out in triplicate.

\section{Results and Discussion}

\section{DPPH antioxidant activity}

2, 2 Diphenyl 1-1-hydrazyl (DPPH) reagent is a stable free radicle and turn into diamagnetic molecule when it takes hydrogen radical or an electron [10]. DPPH test was performed as explained by Souri. Reactive oxygen species is the byproduct of photosynthesis and photorespiration. The reactive oxygen species are alkoxy radical, hydroxyl, superoxide and peroxy radicals. There environmental stresses like nutritional limitations, pollutions, drought, excessive light and temperature cause increase in reactive oxygen species. There are few dangerous diseases caused by oxidative stress in human like cardiovascular diseases, cancer, lipid, protein and DNA damage in human [11]. There was need to develop drugs for the scavenging of these radicals. The standard techniques were used to analyze the antioxidant potential in the extracts of roots of Ricinus communis (Tables 1-3) (Figure 1).

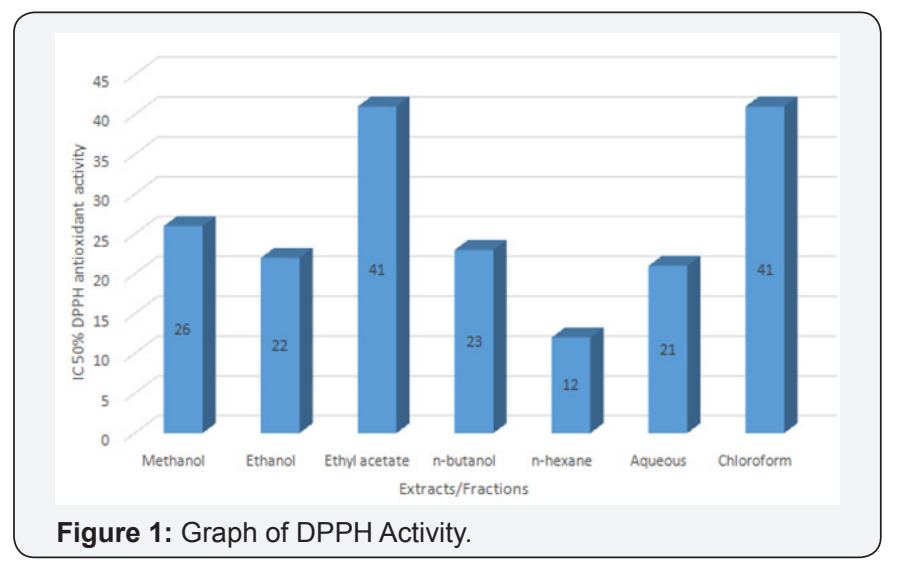

Table 1: Table of DPPH activity.

\begin{tabular}{|c|c|c|}
\hline Sr. No. & Fractions & Mean \pm SE \\
\hline 1 & Methanol & $0.645 \pm 0.033$ \\
\hline 2 & Ethyl acetate & $0.511 \pm 0.031$ \\
\hline 3 & n-hexane & $0.864 \pm 0.018$ \\
\hline 4 & Chloroform & $0.519 \pm 0.029$ \\
\hline 5 & Ethanol & $0.678 \pm 0.005$ \\
\hline 6 & $n$-butanol & $0.674 \pm 0.013$ \\
\hline 7 & Aqueous & $0.689 \pm 0.018$ \\
\hline 8 & Control & $0.872 \pm 0.015$ \\
\hline
\end{tabular}

Table 2: Analysis of Variance for DPPH activity.

\begin{tabular}{|c|c|c|c|c|c|}
\hline \multicolumn{5}{|c|}{ Analysis of variance table for DPPH antioxidant activity } \\
\hline Sr. No. & $\begin{array}{c}\text { Source of } \\
\text { variance }\end{array}$ & $\begin{array}{c}\text { Degrees } \\
\text { of } \\
\text { freedom }\end{array}$ & $\begin{array}{c}\text { Sum of } \\
\text { squares }\end{array}$ & $\begin{array}{c}\text { Mean } \\
\text { squares }\end{array}$ & F-value \\
\hline 1 & Treatment & 7 & 0.379159 & 0.054166 & $36.31^{* *}$ \\
\hline 2 & Error & 16 & 0.023869 & 0.001492 & \\
\hline 3 & Total & 23 & 0.403028 & & \\
\hline
\end{tabular}

${ }^{* *}=$ Highly significant $(P<0.01)$.

Table 3: Table of IC 50 value of Plant.

\begin{tabular}{|c|c|c|}
\hline Sr. No & Fractions & \% of age activity \\
\hline 1 & Methanol & 26 \\
\hline 2 & Ethanol & 22 \\
\hline 3 & Ethyl acetate & 41 \\
\hline 4 & $n$-butanol & 23 \\
\hline 5 & $n$-hexane & 12 \\
\hline 6 & Aqueous & 21 \\
\hline 7 & Chloroform & 41 \\
\hline
\end{tabular}

Data represented as percentage

The bark of Ricinus communis was analyzed for DPPH activity. The aqueous and ethanolic extracts were analyzed. They showed $50 \%$ and $68 \%$ radical scavenging activity [12]. The aqueous, methanol and ethanol extracts of bark of Ricinus communis were analyzed for DPPH activity. The acvitiy was seen as 50\%, 53\% and $44 \%$ [13]. In my analysis, the seven extracts were taken from roots of Ricinus communis showed DPPH scavenging activity. The ethyl acetate and chloroform showed maximum activity with $41 \%$ reults. The remaining was effective but they were less effective than these two.

\section{Total Phenolic Content}

Phenols are important elements of plants which are universally distributed in species of plants. The quantitative and qualitative investigation of main phenolics in plants might be supportive in illuminating the relations between TPC and total antioxidant activity of the extracts [14]. Polyphenolic substances inhibit mutagenesis and carcinogenesis in individuals. FolinCiocalteu method was used to determine TPC Chaharedhi et al. 
[5] and end results were stated as gallic acid equivalents (mg gallic acid per gram of dry mass). This method was selected because of its intensity and quickness to measure phenolics. The free radicals in excessive quantity are cause of ageing. They cause numerous diseases. It is due to lack of antioxidant activity. The antioxidants obtained from plants are considered as better as compared to synthetic ones. There are antioxidants with low molecular mass. They are considered as good against oxidative stress [15]. The total phenolic content is technique to measure antioxidant activity of secondary metabolites present in the plants. The standard process was used to analyze it (Tables 4-6) (Figure 2).

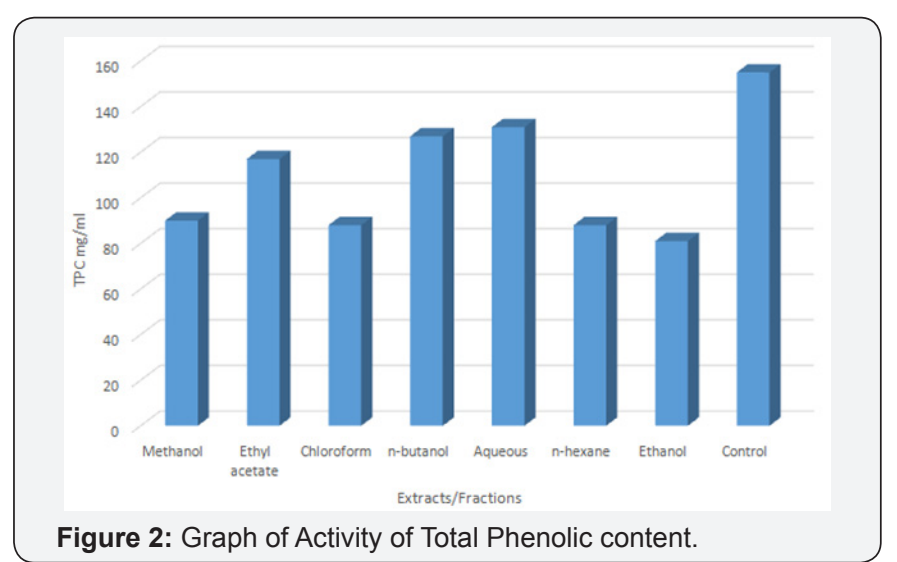

Table 4: Table of Mean values for Total phenolic content of test fractions.

\begin{tabular}{|c|c|c|}
\hline Sr. No. & Treatment & Mean \pm SE \\
\hline 1 & Methanol & $0.550 \pm 0.042$ \\
\hline 2 & Ethyl acetate & $0.683 \pm 0.004$ \\
\hline 3 & $n$-hexane & $0.540 \pm 0.012$ \\
\hline 4 & Chloroform & $0.538 \pm 0.012$ \\
\hline 5 & Ethanol & $0.505 \pm 0.021$ \\
\hline 6 & $n$-butanol & $0.733 \pm 0.034$ \\
\hline 7 & Aqueous & $0.754 \pm 0.012$ \\
\hline 8 & Control & $0.872 \pm 0.015$ \\
\hline
\end{tabular}

Data represented as \pm standard error.

Table 5: Table of Activity of Total phenolic content.

\begin{tabular}{|c|c|c|}
\hline Sr. No. & Fraction & Content \\
\hline 1 & Methanol & 90 \\
\hline 2 & Ethyl acetate & 117 \\
\hline 3 & Chloroform & 88 \\
\hline 4 & $n$-butanol & 127 \\
\hline 5 & Aqueous & 131 \\
\hline 6 & $n$-hexane & 88 \\
\hline 7 & Ethanol & 81 \\
\hline 8 & Control & 155 \\
\hline
\end{tabular}

Data represented as $\mathrm{mg} / \mathrm{mL}$ gallic acid equivalent.
Table 6: Analysis of Variance for Total phenolic contents.

\begin{tabular}{|c|c|c|c|c|c|}
\hline \multicolumn{5}{|c|}{ Analysis of variance table for TPC } \\
\hline Sr. No. & $\begin{array}{c}\text { Source of } \\
\text { variance }\end{array}$ & $\begin{array}{c}\text { Degrees } \\
\text { of } \\
\text { freedom }\end{array}$ & $\begin{array}{c}\text { Sum of } \\
\text { squares }\end{array}$ & $\begin{array}{c}\text { Mean } \\
\text { squares }\end{array}$ & F-value \\
\hline 1 & Treatment & 7 & 0.601407 & 0.085915 & $56.78^{* *}$ \\
\hline 2 & Error & 16 & 0.024211 & 0.001513 & \\
\hline 3 & Total & 23 & 0.625618 & & \\
\hline & & & & & \\
\hline
\end{tabular}

${ }^{* *}=$ Highly significant $(\mathrm{P}<0.01)$.

The Myrtus communis leaves were analyzed for total phenolic content. The aqueous, methanol and ethanol extracts were analyzed. They showed activity between 9 to $36 \mathrm{mg}$ GAE per gram [16]. The six extracts of Ricinus communis stem were analyzed. The activity was ranged between $97 \mathrm{mg} / \mathrm{mL}$ to $133 \mathrm{mg} / \mathrm{mL}$. The control showed $175 \mathrm{mg} / \mathrm{mL}$ activity. The Torilis leptophyla was analyzed for TPC. The extracts of $n$-hexane, chloroform and n-butanol were analyzed. They showed $121 \mathrm{mg}$ GAE/g to $147 \mathrm{mg}$ GAE/g [17]. In my analysis, I used seven extracts. All the extracts showed activity but the aqueous, $n$-butanol and ethyl acetate extracts showed activity of $131 \mathrm{mg} / \mathrm{mL}, 127 \mathrm{mg} / \mathrm{mL}$ and 117 $\mathrm{mg} / \mathrm{mL}$ respectively. Other extracts gave less activity than this and control gave $155 \mathrm{mg} / \mathrm{mL}$.

\section{Total Flavonoids Contents}

Flavonoids possess a broad variety of biological and pharmacological activities. These are able to function as reducing agents, quenchers of singlet oxygen, metal chelators, scavengers of ROS and chain-breaking antioxidants [18]. These flavonoids have inhibitory efficiency against micro organisms which are the reason to cause plant aliments. This technique has been utilized by researchers for the TFC value estimation [19]. There are various inflammatory diseases, nervous diseases and rheumatism that can be cured by the use of antioxidants [20] (Tables 7-9) (Figure 3). The leaf extract of Ricinus communis was for total flavonoid content analysis. The methanol, ethanol and benzene extracts were taken. The catechin equivalent activity of 17 to $28 \mu \mathrm{g} / \mathrm{ml}$ was seen [21]. The leaf extracts of Ricinus communis were analyzed. The petroleum ether, methanol and aqueous extracts were used. They showed catechin equivalent activity of 23 to $37 \mu \mathrm{g} / \mathrm{ml}$ [22]. In my analysis for TFC activity. In my analysis, the control gave $38 \mu \mathrm{g} / \mathrm{ml}$. The methanol and aqueous showed $32 \mu \mathrm{g} / \mathrm{ml}$ each. Remaining extracts gave less activity than this. Ricinus communis is considered as a good medicinal plant. It has good antioxidant activity. 
Table 7: Table of Total flavonoid contents of test fractions.

\begin{tabular}{|c|c|c|}
\hline Sr. No. & Fractions & Mean \pm SE \\
\hline 1 & Methanol & $0.733 \pm 0.017$ \\
\hline 2 & Ethyl acetate & $0.517 \pm 0.015$ \\
\hline 3 & $n$-hexane & $0.341 \pm 0.013$ \\
\hline 4 & Chloroform & $0.447 \pm 0.026$ \\
\hline 5 & Ethanol & $0.547 \pm 0.052$ \\
\hline 6 & $n$-butanol & $0.611 \pm 0.033$ \\
\hline 7 & Aqueous & $0.752 \pm 0.025$ \\
\hline 8 & Control & $0.872 \pm 0.015$ \\
\hline
\end{tabular}

Data represented as \pm standard error.

Table 8: Table of Total flavonoid contents Catechin equivalent.

\begin{tabular}{|c|c|c|}
\hline Sr. No. & Fractions & Content \\
\hline 1 & Methanol & 32 \\
\hline 2 & Ethanol & 23 \\
\hline 3 & n-butanol & 26 \\
\hline 4 & Aqueous & 32 \\
\hline 5 & n-hexane & 14 \\
\hline 6 & Chloroform & 19 \\
\hline 7 & Ethyl acetate & 22 \\
\hline 8 & Control & 38 \\
\hline
\end{tabular}

Data represented as $\mu \mathrm{g} / \mathrm{mL}$ catechin equivalent.

Table 9: Table of ANOVA for Total flavonoid contents.

\begin{tabular}{|c|c|c|c|c|c|}
\hline \multicolumn{6}{|c|}{ Analysis of variance table for TFC } \\
\hline Sr. No. & $\begin{array}{c}\text { Source of } \\
\text { variance }\end{array}$ & $\begin{array}{c}\text { Degrees } \\
\text { of } \\
\text { freedom }\end{array}$ & $\begin{array}{c}\text { Sum of } \\
\text { squares }\end{array}$ & $\begin{array}{c}\text { Mean } \\
\text { squares }\end{array}$ & F-value \\
\hline 1 & Treatment & 7 & 0.90728 & 0.12961 & $57.66^{* *}$ \\
\hline 2 & Error & 16 & 0.03597 & 0.00225 & \\
\hline 3 & Total & 23 & 0.94325 & & \\
\hline
\end{tabular}

** = Highly significant $(P<0.01)$.

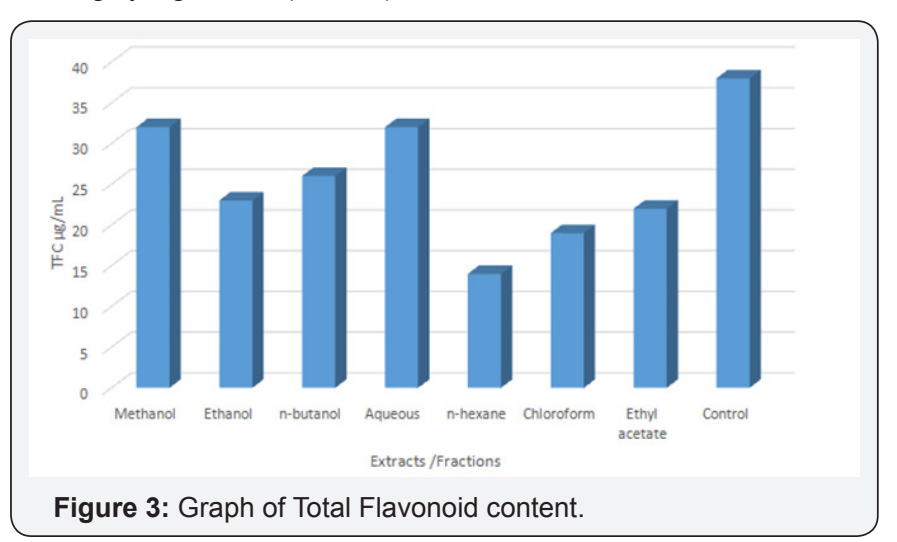

\section{Outcomes}

Total phenolic contents were determined by Folin-Ciocalteu reagent method. The total flavonoid contents were determined by using Aluminum Chloride colorimetric technique and DPPH radical scavenging was determined. The roots of Ricinus communis were used to check its potential for antioxidant activity. Seven extracts were prepared and extracts from roots of Ricinus comunis showed good antioxidant activity. In TPC all seven extracts taken from roots of Ricinus communis gave good activity. In all seven extracts aqueous, $n$-butanol and ethyl acetate gave a better activity. Aqueous gave $131 \mathrm{mg} / \mathrm{mL}, n$-butanol $127 \mathrm{mg} /$ $\mathrm{mL}$, ethyl acetate $117 \mathrm{mg} / \mathrm{mL}$ and control $155 \mathrm{mg} / \mathrm{mL}$ gallic acid equivalent. It was seen that extracts taken from roots of Ricinus communis gave less than the control but still it had shown a good comparable activity.

In TFC activity methanol and aqueous extracts showed a good activity and all other extracts showed less activity than this. Methanol gave $32 \mu \mathrm{g} / \mathrm{mL}$, aqueous $\mu \mathrm{g} / \mathrm{mL}$ control $38 \mu \mathrm{g} / \mathrm{mL}$ catechin equivalent. Control gave better activity than all extracts here too but the extracts taken from roots of Ricinus communis had also shown good comparable activity. In DPPH activity, the IC 50 value for ethyl acetate was $41 \%$ and chloroform $41 \%$. These two extracts showed good activity. Remaining all the samples had also shown good comparable DPPH activity. It had shown that roots of Ricinus communis have good antioxidant potential. It could be used as good antioxidant agent in medicinal analysis.

\section{Literature Cited}

1. Bolaji Z, S Gana, K Andrew, AO Benson (2012) Castor oil plant (Ricinus communis) botany, ecology and uses. Int J Sci Res 3(5): 020132065.

2. Ndhala AR, M Moyo, JV Staden (2010) Natural antioxidants are fascinating or mythical biomolecules. J Mol 15(10): 6905-6930.

3. Shargorodsky M, O Debby, Z Mattas, R Zimlichman (2010) Effect of long term treatment of antioxidants (vitamin C, vitamin E, coenzyme Q and selenium) on arterial compliance, humoral factor and inflammatory markers in patients with multiple cardiovascular risk factors. Nutrition and metabolism 7: 55-63.

4. Ainsworthy EA, KM Gallespie (2007) Estimation of total phenolic content and oxidation substrates in plant tissues using Folin ciocalteu reagent. Natur Prot 2(4): 875-877.

5. Chahardehi AM, D Ibrahim, SF Suleman (2009) Antioxidant activity and polyphenolic contents of some medicinal plants in Urticaceaae family. J Bio Sci 3: 25-29.

6. Pontis JA, LA Mendonca, AD Costa, SJRD Silva, A Flach (2014) Color, phenolics and flavonoid content and antioxidant activity of honey from Roraima, Brazil. Food Sci Tech 34: 69-73.

7. Siddique NA, M Mujeeb, AK Najmi, M Akram (2010) Evaluation of antioxidant activity, quantitative estimation of phenols and flavonoids in different parts of Aegle marmelos. Afr J Plant Sci 4: 001-005.

8. Queiroz YS, EY Ishimoto, DHM Bostos, GR Sempaio, EAFS Torres (2009) Garlic (Allium sativum) and ready to eat garlic products in vitro antioxidant activity. J Food Chem 115(1): 371-374.

9. Souri EG, G Amin, H Farsan, H Jalalizadeeh, S Barezi (2008) Screening of thirteen medicinal plants extracts for antioxidant activity. Iran J Pharm Res 7(2): 149-154.

10. Bhalodia NR, PB Nariya, RN Acharya, VJ Shukla (2011) Evaluation of in vitro antioxidant activity of flowers of Cassia fistula Linn. Int J PharmTech Res 3(1): 589-599.

11. Marxen K, KH Vanselow, S Lippemeir, R Hintze, A Rauser, et al. (2007) Determination of DPPH radical scavenging caused by methanolic extract of some microalgal species by linear regression analysis of spectrophotometric measurements. J Senssors 7(10): 2080-2095. 
12. Garg V, N Verma, S Sharma (2014) In vitro Bio efficacy of hydro ethanolic extract of Ricinus communis bark and root for antioxidative and antihyperglycemic potential. J App Sci Res 2: 100-108.

13. Singh RK, MK Gupta, D Katiyar, A Srivastav, P Singh (2010) In vitro antioxidant activity of successive extracts of Ricinus communis stems. Int J Pharma Sci Res 1: 100-103.

14. Demiray S, ME Pintado, PML Castro (2009) Evaluation of phenolic profiles and antioxidant activities of Turkish medicinal plants: Tilia Argentena, Crataegi Folium leaves and Polygonum Bistorta roots. World Acad Sci Eng Technol 3(6): 312-322.

15. Hossain MA, MD Shah (2015) A study on total phenols content and antioxidant activity of essential oil and different solvent extracts of endemic plant Merremia borneensis. Arab J Chem 8(1): 66-71.

16. Amensour M, E Sendra, J Abrini, S Bouhdid, JAP Alveraz, et al. (2009) Total phenolic content and antioxidant activity of myrtle (Myrtus communis) Extracts. J Natur Prod Communic 4(6): 819-824.

17. Saeed N, MR Khan, M Shabir (2012) Antioxidant activity, total phenolic content and total flavonoid contents of whole plant extracts of Torilis leptophyla. Compl Altern Med 12: 221-223.

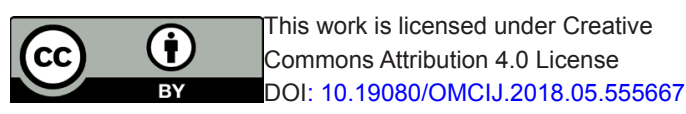

18. Naseer R, B Sultana, F Anwar, Z Mehmood, M Mushtaq (2014) Variations in phenolics, antioxidant and antifungal activities among different parts of selected medicinal plants. Pak J Bot 46(2): 705-712.

19. Ghimeray AK, C Jin, BK Ghimire, DH Cho (2009) Antioxidant activity and quantitative estimation of azadirachtin and nimbin in Azadirachta Indica A. Juss grown in foothills of Nepal. Afr J Biotechnol 8: 30843091.

20. Madan R, G Bansal, S Kumar, A Sharma (2011) Estimation of total phenols and flavonoids in extracts of Actaea spicata roots and antioxidant activity study. Ind J Pharm Sci 73(6): 666-669.

21. Rao N, S Mittal, Sudhaanshu, E Menghaani (2013) Assessment of phytochemical screening, antioxidant and antibacterial potential of methanolic extracts of the Ricinus communis. Asia J Pharm Tech 3(1): 20-25.

22. Chakarborthi GS (2008) Antioxidant activity of the successive extracts of Ricinus communis leaves. J Envi Res Develop 3(2): 537-539.

\section{Your next submission with Juniper Publishers} will reach you the below assets

- Quality Editorial service

- Swift Peer Review

- Reprints availability

- E-prints Service

- Manuscript Podcast for convenient understanding

- Global attainment for your research

- Manuscript accessibility in different formats ( Pdf, E-pub, Full Text, Audio)

- Unceasing customer service

Track the below URL for one-step submission https://juniperpublishers.com/online-submission.php 